\title{
Anorexia and Depression: Depressive Comorbidity in Anorexic Adolescents
}

\author{
Carmen García-Alba \\ José Germain Psychiatric Institute of Leganés, Madrid
}

Frequently, depression is a concomitant pathology in anorexia nervosa. To verify this, we carried out a comparative case/control study with 50 anorexic patients, restricting-type (ANP), 50 depressed patients (DP) and 50 non-patients (NP), aged between 13 and 16. We used the Rorschach Test and the Minnesota Multiphasic Personality Inventory (MMPI) and compared the results to parent's observations collected from the Achenbach Child Behavior Checklist (CBCL). Results showed two clearly different groups among participants: ANP with depression (36\%) and ANP without depression (64\%). This seems to indicate that depression is not a core element in anorexic disorders. However, we also observed a significant increase in the MMPI scale 2, which was probably related to starvation and weight loss. We confirmed the absence of general anxiety in the ANP group and obtained differences between depressive symptoms and those derived from coping deficit disorders. The discussion emphasizes the importance of using several tests to reduce bias in results and conclusions.

Keywords: anorexia nervosa, depression, assessment, adolescents, Rorschach Test, MMPI

La depresión es, frecuentemente, una patología concomitante con la anorexia nerviosa. Para verificarlo, se diseñó un estudio comparativo con 50 pacientes anoréxicas, tipo restrictivo (ANP), 50 deprimidas (DP) y 50 no pacientes (NP), de edades comprendidas entre los 13 y 16 años. Se utilizaron el Test de Rorschach y el Minnesota Multiphasic Personality Inventory (MMPI), comparándose los resultados con las observaciones de los padres, recogidas de forma estandardizada a través del Child Behavior Checklist (CBCL). Los resultados obtenidos mostraron la existencia de dos grupos claramente diferenciados: ANP con depresión (36\%) y ANP sin depresión (64\%). Por lo tanto, parece que la depresión no es nuclear en la patología anoréxica. No obstante, se apreció un aumento significativo de la escala 2 del MMPI, probablemente consecutivo a la inanición y pérdida de peso. Además, en el grupo ANP se ha constatado la ausencia de ansiedad generalizada. También se encontraron diferencias entre el síndrome depresivo y las alteraciones derivadas de la indefensión social. Igualmente, se ha subrayado la importancia de investigar con distintos tests, para evitar sesgos en los resultados y conclusiones. Palabras clave: anorexia nerviosa, depresión, evaluación, adolescentes, Test de Rorschach MMPI

This article is part of a wider research project that formed the basis of a doctoral dissertation. (García-Alba, 2000). My sincere thanks to Dr. John Exner and Dr. Concepción Sendín, for their continuous help and support during this research. Their opinions on the results obtained have contributed substantially to my interest in publishing them.

Correspondence concerning this article should be addressed to Carmen Garcia-Alba, Ronda Delicias 21, Majadahonda, 28220 Madrid (Spain). Fax: 91638 0243. E-mail: garciaalba@wanadoo.es 
The relationship between anorexia (AN) and depression (D) cannot be denied, since the two disorders share a series of biological anomalies such as: 1) hypercorticism associated with an excessive excretion of the corticotrophin-releasing hormone (CRH), 2) a dysfunction of the neurotransmitters (low noradrenalin and serotonin levels), and 3) an abnormal dexamethasone suppression test (Díaz, 1999). However, the precise nature of this relationship and the sequence in which it tends to develop still remain unclear (Cervera \& Gual, 1998; Chinchilla, 1995).

It was in 1977 when Cantwell, Sturzenberger, Burroughs, Salkin, and Green suggested the possibility of considering some AN cases as a subtype of a mood disorder. Since then, this connection has been studied from many different perspectives, which explains the variety of results obtained, none of them conclusive. Thus, Chinchilla (1977) considers $\mathrm{AN}$ to be a depressive equivalent, that is, as a psychopathological manifestation of an underlying depressive disorder. On the other hand, Altshuler and Weiner (1985) argue that $\mathrm{AN}$ is not a variant of $\mathrm{D}$, and maintain that the discrepancies in the results obtained are due to the fact that the studies carried out suffer from serious methodological problems, such as lack of uniformity of criteria in the diagnosis of $\mathrm{D}$ and the overlapping of criteria for AN and D. Katz (1987) points out that in some cases, affective disorders would represent one of the many risk factors for the development of an eating disorder (ED), and in others, the malnutrition that accompanies EDs may result in a state comparable to that of major depression. This author concludes that, when both diagnostic criteria are present, both should be considered. Through family studies, a relationship between AN and a family risk for D has been detected, with a prevalence of $\mathrm{D}$ in biological first-degree relatives of anorexic patients in $22 \%$ of the cases (Gershon et al., 1984; Winokur, March, \& Mendels, 1980), compared with $7-10 \%$ in the control groups. The existence of a possible predisposition or genetic vulnerability to anorexia has been suggested, though it has yet to be shown (Toro, 1995).

Nevertheless, some studies stress the differences between the two disorders, and consider D to be a pathology associated with AN (López, 2001; Morandé et al., 1995). They speak of depressive comorbidity, in reference to the existence of a clearly defined and diagnosed disorder according to consensual and operative criteria, which is constituted as an entity distinct from EDs, even though it appears concomitantly. It is considered that depressive symptomatology may be a consequence of malnutrition itself (Toro, 2001), with an improvement in mood being observed when patients regain weight (López, 2001). However, there is not total consensus, since other authors (Pollice, Kaye, Greeno, \& Weltzin, 1997) report that malnutrition intensifies a series of symptoms such as depression, anxiety and obsessive traits, which are found with more intensity at the onset of AN. These symptoms become less pronounced with weight gain. Though mitigated, the symptoms persist long- term, leading these authors to conclude that malnutrition intensifies the symptoms and that they are possibly linked to the anorexic pathology itself. A greater tendency to present major depressive episodes in those patients who, at some point, have displayed purging behaviors than in those who present a purely restrictive condition has also been reported (Halmi, Eckert, Marchi, Sampugnaro, Apple, \& Cohen, 1991). It is considered that younger restrictive anorexics display greater anxiety and depression than older anorexics (Heebink, Sunday, \& Halmí, 1995).

Research shows that many patients suffering from AN have been diagnosed with $\mathrm{D}$ at some point in their lives, but the figures provided vary substantially depending on the author and the criteria used, not only in the definition of this diagnostic category, but also in the method used to evaluate it. Thus, Katz (1987) provides figures varying between 25 and 75\%; the American Psychiatric Association (APA, 1993) places the percentage between 50 and $75 \%$; and Turón (1997) situates this figure around 69\%. The diagnostic criteria are commonly based on the Diagnostic and Statistical Manual of Mental Disorders (APA, 1987,1994), and the tests used in the psychological evaluation are usually personality questionnaires or inventories (Dancyger, Sunday, \& Halmi, 1997), or more specific anxiety/depression (Berk, Kessa, Szabo, \& Burtow, 1997) or ED scales (Calderón, 2000). For obvious reasons of difficulty and cost (financial costs, time consumption and degree of training required), more exhaustive psychodiagnostic studies are scarce.

A critical study of reviewed research reveals a series of disadvantages. The sample size of the evaluated participants is usually small (Varela, Martini, Ponce, \& Rubio, 1994), the age range of participants is excessively broad, thus mixing subjects who have widely differing psychological traits (Muttini, 2002); and above all, the subtypes of AN (restrictive and binge-eating/purging) are usually mixed together (Cabetas, 1998). Other common inconsistencies include placing patients with different characteristics in the same group -outpatients and inpatients- (Horiguchi \& Sasaki, 1998), or failing to take into account, or to specify, the evolutionary stage of the illness (Mormont, Frankignoul, \& Michel, 2001). In other cases, the normative data of the tests, which should be used only as guidelines or references, is used as a non-patient control group (Salorio et al., 2003). We know that, in such cases, significant differences can be obtained as a consequence of the comparison between heterogeneous groups (that of the normative data) and more homogeneous groups (the participants in the study), which can lead to erroneous conclusions (Dies, 1995; Exner, 1995).

For all of these reasons, it seemed interesting to explore the relationships between $\mathrm{AN}$ and $\mathrm{D}$, through a comparative design of cases and controls, using, in addition to personality questionnaires (MMPI), a test such as the Rorschach. This test reveals the structure and organization of the participant's personality through the articulation of subtle perceptual 
properties, without him or her knowing exactly what type of information he or she is providing, thus precluding its deliberate alteration. Moreover, data from the Rorschach Test can subsequently be analyzed statistically by means of a computer program.

We hypothesize that there are significant differences between AN and D. Mainly, that they are distinct nosological entities, and that, therefore, they will be differentiated in the depression indicators we shall use for assessing them.

\section{Method}

\section{Participants}

Participants were adolescent women, as the anorexic pathology has a higher incidence in females (Garner \& Garfinkel, 1985). The male group, evaluated in parallel, is still quite a meager group, and will therefore be examined in future studies and comparisons. The selected age of participants, between 13 and 16 years, was aimed to: a) eliminate childhood AN, which has a different significance, generally as a means of protest against one's immediate context; b) obtain data at the onset of the illness, in order to avoid the influence of other variables, such as chronic development (Lázaro \& Toro, 1999); and c) to cover a developmental period marking significant changes in physical, mental and educational functioning, without it being too broad (Achenbach, 1979), so as to eliminate differences related to age.

Participants were distributed into three groups of fifty following the criteria of Dies (1995) and Exner (1995): 50 patients diagnosed with anorexia nervosa, restricting-type (ANP), 50 patients diagnosed with depression (DP), and finally, 50 non-patients (NP) as a control group. The ANP group had a mean age of 14.84 years $(S D=1.13)$; the DP group had a mean age of 15.02 years $(S D=1.13)$; and the mean age of the NP group was 14.90 years $(S D=0.95)$. They came from the public sector (educational or health care), and their socio-economic level was around middle to lower-middle. A check on the Rorschach cognitive data was carried out, as proposed by Sendín and García-Alba (1995), in order to confirm the absence of intellectual limitations.

The specific criteria determining the cases in each group are listed below.

1. Anorexic Patients (ANP): a) Patients were diagnosed following the criteria of the DSM III-R (APA, 1987) which was the latest version available at the start of this research. When the DSM IV appeared (APA, 1994), all DSM III-R criteria were revised in light of the new publication, showing that there were hardly any significant changes in these criteria. Only the subtypes of restricting AN and bingeeating/purging AN were added, modalities which had already been taken into consideration at the start of the research; b) Restricting-type anorexic subjects, (who lose weight only by restricting food, not by purging), where the influence of the binge-eating/purging variable has been eliminated. The elimination of this variable delayed fieldwork considerably, as $50 \%$ of anorexic patients develop bulimic symptoms (APA, 1993), causing a symptomatic alternation in one direction or the other. The interview conducted at the beginning of the evaluation of these patients was effective in discarding all these cases; c) First hospitalization due to the anorexic problem was considered so as to avoid doubtful diagnosis, as well as already chronic cases.

These participants were recruited at the University Hospital of Getafe, the Hospital of Móstoles and the University Hospital Niño Jesús (all in the city or region of Madrid, Spain). The latter institution is a pioneer in the treatment of infant-juvenile AN in Spain.

2. Patients diagnosed with depression (DP). These were selected following the clinical criteria of the DSM III-R (APA, 1987), and its revised version (APA, 1994). The clinical criteria are the most widely accepted (Roberts, Vargo, \& Ferguson, 1989), even though the nosological problem of this pathology in infancy and adolescence has not yet been solved (García Villamisar \& Polaino, 1988). No differences were established between major depression and dysthymic disorder due to the difficulties involved in this differentiation, especially within the child and juvenile population (APA, 1994), and due to its lack of utility for the purposes of this research.

These participants were recruited from two Mental Health Centers in Madrid (Leganés and Fuenlabrada), both of which have specialized staff and facilities for infant and juvenile care.

3. Control group (NP). The control group includes: a) individuals who have never required any psychiatric or psychological assistance; and b) individuals with adequate academic performance, in order to eliminate possible intellectual limitations (non-repeaters).

These participants were recruited from a Secondary School in Madrid (Leganés), with prior application for informed parental consent. It was agreed beforehand that if, after the psychological assessment was made, researchers detected any type of mental pathology in any of the adolescents, the case could be referred to the Infant-Juvenile Team at the Mental Health Center in the area, so that the adolescent in question received the appropriate psychological attention.

\section{Instruments}

The aim was to obtain information from different sources, all of them complementary to one another (Dana \& Bolton, 1982). Psychological tests selected as measurement instruments were the Rorschach Test and the MMPI. Both of these tests were fully administered and coded, but, from all the Rorschach and MMPI information, we analyzed only those variables directly related to depression and to the validity criteria of the tests themselves. 
Anxiety measures were also included, for two reasons: a) anxiety components are frequently found in depressive patients, regardless of age (Polaino \& García Villamisar, 1988); and b) according to some authors, these can also be found in ED (Cervera \& Quintanilla, 1995).

The Rorschach Test. This test is basically used as a perceptual-cognitive measure, and follows the guidelines of Exner's Comprehensive System ( Exner, 1986, 1993, 2003). We analyzed the following aspects:

1. Number of Responses (R) and Lambda (L), given their relationship to the Rorschach protocol validity. $\mathrm{L}$ is a ratio that relates to issues of economizing the use of resources. First, we considered every protocol with $\mathrm{R}<14$ and $\mathrm{L}>.99$ as not valid, following the Comprehensive System criteria (Exner, 1993, 2003).

2. The Depression Index (DEPI), which is composed of 14 variables. Among these variables, five are related to affect, six to cognitive features and the other three concern interpersonal relationships/psychological complexity (Exner, 1997). Its critical cut-off point is DEPI $\geq 5$ (Exner, 1993), and it identifies $85 \%$ of depression cases, of which $71 \%$ show DEPI $\geq 6$. This is why we used DEPI $\geq 6$ (Exner, 1993), as a stricter critical point. Nevertheless, to provide more information, DEPI $\geq 5$ was included in the data analysis, even though it refers to more temporary and more reactive-affective problems.

3. Even though the Coping Deficit Index (CDI) is not, in itself, a depression index, it is useful for identifying those individuals whose helplessness and lack of social skills may make them seem depressed, and those in which the depressant elements are usually the result of a more general social incompetence problem that may lead to real depression if not solved (Exner \& Sendín, 1998). The CDI is composed of 11 variables and identifies $79 \%$ of the cases with a diagnosis of affective disorder, but which do not show a positive DEPI (Exner, 1993). Its critical cut-off point is CDI $\geq 4$, and it relates to social difficulties.

The simultaneous combinations of positive DEPI and CDI indexes (Exner, 1997) were also analyzed, in order to determine the relationship between depression and social inefficiency in the studied samples. Regarding participants who scored positively on both indexes, we know that depression is the result of their problems regarding lack of social skills. They also present different psychological characteristics from those individuals for whom only one of the two indexes was positive. When DEPI $\geq 5$ and CDI $\geq 4$ are used together, they can identify $93 \%$ of depression cases (Exner, 1997).

4. We also analyzed the 26 variables included in the DEPI and CDI indexes separately, with their critical points showing clinical evidence. Among these variables, the most significant for this research are those that indicate a possible presence of anxiety. These variables are:

Achromatic color (C') (Exner, 1993, 2003): These responses are based on the gray, black or white features of the blot, used as colors. A C' response appears in $82 \%$ of the normative sample from age 13 to 16 (Exner \& Weiner, 1995). This is a fairly stable variable, with re-test correlations ranging from .60 to .70 (Exner, 1993). The increase in this type of response $\left(\mathrm{C}^{\prime}>2\right)$ represents a form of non-deliberate emotional constriction, present in psychosomatic and depressive patients and, to a lesser extent, in obsessive patients (Exner \& Sendín, 1998).

All Shading responses (Sum SH): The light-dark features of the blot, or the shading components, represent texture, depth or dimensionality. Exner and Weiner, in their normative data (1995), report a mean score of 3.51 for those aged 13 to 16. A considerable increase in this type of response indicates the presence of an irritating or disturbing affect that is recorded as mental suffering (Exner, 1993, 2003); in order to reveal its intensity and origin, a further analysis of the different variables of which it is composed is required (Exner \& Sendín, 1998).

Parker, Hanson, and Hunsley (1988), applying Hedges and Olkin's (1985) procedures and revising 411 studies, found convergent validity coefficients of .41 for the Rorschach Test. With regard to the reliability of the test, Exner and Weiner (1995) carried out several test-re-test studies, reporting correlations from .81 to .89 for 13 core variables.

Minnesota Multiphasic Personality Inventory (MMPI). The MMPI is a self-report inventory with a fixed-response format. It points out the presence or absence of symptoms and behaviors in psycho-pathological diagnostic categories. The individual communicates what $\mathrm{h} / \mathrm{she}$ knows about $\mathrm{him} / \mathrm{h}$ erself and what $\mathrm{h} / \mathrm{she}$ is willing to reveal. The MMPIA (Archer, 1992), a specific adolescent version, was not used because it has not been translated into Spanish or adapted to the Spanish population, although it contains more adolescent-relevant items, such as, an additional depression content scale (A-dep) and some items related to disordered eating.

Hathaway and McKinley (1951) stated that a high score on an MMPI scale has been found to positively predict the corresponding final clinical diagnosis in more than $60 \%$ of new psychiatric admissions. This optimistic prediction was never verified. In fact, the concept of the two-point code type, which was stated in the beginning, attempted to escape from the misleading diagnostic connotations of the original scale labels by assigning numbers to the scales. However, code typology was not much more successful as a diagnostic tactic than the use of single scales (Levitt, 1989). The next step was the development of rules based on all or most of the clinical scales, such as that of Harris and Lingoes (Levitt, 1989). Unfortunately, as Greene (1980) pointed out, research with these scales, especially studies on validity, is scarce and no empirical studies have been conducted on these measures in adolescent populations (Archer, 1992).

As recommended by Archer (1987), in this study the MMPI was fully applied, and the Marks and Briggs (1972) 
adolescent norms were used, as they seem to be the most appropriate according to several authors (Archer, 1987; Klinefelter, Pancoast, Archer, \& Pruitt, 1990). We selected the following variables:

1. Validity scales

Scale F: This scale is often referred to as the frequency or infrequency scale, and includes a wide variety of obvious items involving bizarre, strange or unusual experiences, thoughts and sensations.

Scale K: This scale was selected to identify individuals who display significant degrees of psychopathology but tend to produce profiles that are within normal limits.

Index F - K > 11 (Gough, 1950): The idea is that if F is substantially higher than $\mathrm{K}$, the respondent is "faking", or trying to exaggerate psychopathology.

Considerations on record validity follow the Archer (1987) criteria for adolescents. In the Hedges and Olkin (1985) study, they showed convergent validity correlation coefficients of .46 for MMPI validity scales.

2. Scale 2 (Depression) and scale 7 (Psychasthenia). No MMPI clinical scale is designed to measure anxiety, although this role is often assigned to scale 7 (Levitt, 1989). Presence of depression and/or anxiety is determined by a T-score $\geq$ 70. Hathaway and McKinley (1942) offer reliability coefficients of .77 for scale 2 and .74 for scale 7 .

3. Two-Point Code Type: 2-7 / 7-2. Individuals with these profile types are depressed, anxious, tense, and highly self-punishing. They often worry about themselves and are rigidly focused on their personal deficiencies and inadequacies (Archer, 1987).

Child Behavior Checklist (CBCL): Behavior problems scale. The CBCL is used only as an external criterion to evaluate the same symptomatic behaviors observed by parents as, according to the author himself (Achenbach, 1979), the scale is not a diagnostic instrument.

Achenbach's and Edelbrock's (1983) application and correction guidelines were followed. We included the following subscales, whose critical point is T-score $\geq 70$.

1. Depressed, withdrawal

2. Anxious, obsessive

Several studies made with the whole scale, using its relationship to similar instruments as validity criteria (Quay \& Peterson, 1983), showed satisfactory correlations, from .71 to .92 . The reliability of parent score agreement $(r=$ $.90)$ and of test-retest proof $(r=.70)$ were also satisfactory (Achenbach \& Edelbrock, 1983).

\section{Procedure}

Test administration was, in all cases, individual; even the CBCL was applied through a personal interview to increase its reliability and to avoid the possible invalidation of any of the evaluated cases.

The procedure was basically as follows: a) an initial interview with the adolescent; b) individual application of the Rorschach Test; c) instructions given to fill out the MMPI followed by individual application; d) individual application of CBCL to either of the parents; and e) feedback on the results.

In obtaining Rorschach protocols, in some cases, and due to lack of accessibility to groups, the intervention of other evaluators was necessary (1 examiner in the ANP, 2 in the DP and 3 in the NP groups). In this case, the possible influence of this fact (examiner bias) as well as the interscorer reliability, was analyzed.

\section{Data Analysis}

This study focused only on the quantitative data of the tests. For the data analysis, the SPSS/PC+ statistical program was used. Problems arising from the data analysis of the Rorschach Test were known in advance, because many of its variables do not have a normal distribution. Therefore, they can present asymmetric distributions, which invalidate the use of parametric analyses. It is for this reason that the following statistical calculations were included after the exploratory analysis of the variables. Univariate statistics were used in order to observe the distribution of the variables and provide a more solid basis for the type of analysis selected, as well as provide information about the participants (Viglione, 1997). In those Rorschach variables with standard deviation units $\geq 1.96$, both in the skewness and the kurtosis, we used nonparametric statistical measures.

As a parametric technique for comparing groups, we used a one way ANOVA with three levels (groups). In all cases, the participant groups were independent and had equal variances (Keppel, 1991) (Bartlett's test). The Snedecor F and Tukey tests were used with a significance level (a) of .05 . The statistical power and the effect size $(h)$ were also calculated.

The degrees of freedom are not shown in the analysis of variance tables, as they are identical in all cases $(d f=2)$. We included a summary of the univariate statistics corresponding to each variable (Viglione, 1997), for better interpretation of the results.

In this study, when the basic assumption of equal variances was not met, a double solution was adopted: a) logarithmic transformation proposed by Tukey (Sánchez Carrión, 1995), which, if unable to provide equal variance distributions, was not subjected to further possible transformations (Exner, 1991); and b) use of the nonparametric Kruskal-Wallis test. Both results have been included in the tables, given the disadvantages of both options, as the transformations produce scales with questionable interpretation of the quantitative meaning (Exner, 1995) and the Kruskal-Wallis test is less powerful.

In some variables, with many values around zero, the ranges are quite limited and the relationships non-linear. In these cases, Exner (1991) proposes nonparametric statistical measures, and we used chi-square, which we also used in 
the variables in which it was useful to determine a cut-off point to distinguish between the normal values and those which denote some type of psychological disorder.

To provide an in-depth study of the contingency tables, a residual analysis was carried out (Sánchez Carrión, 1992). It is advisable to calculate the contingency coefficient (C) to determine the degree of dependence or co-variance.

\section{Results}

\section{The Rorschach Test}

Reliability and Validity. Table 1 provides information about the percentage of interscorer reliability, and the recommended levels for Exner and Sendín (1997) and for Weiner (1997) are compared with those obtained in this research on $15 \%$ of Rorschach protocols selected at random from the sample total.

Even though only valid protocols were used initially, it is important to point out that there were no significant differences between the groups in reference to $\mathrm{R}$, nor in the
Lambda score, as observed in the analysis of variance performed.

Nevertheless, it is the ANP group who, qualitatively, presented a lower $\mathrm{L}$, under .99 , in $70 \%$ of the protocols, as compared to the DP (64\%) and the NP (52\%) groups. This finding is seen as important, as it allows us to deduce that the data obtained in this group is not shadowed by any evasive and simplifying style, which is characteristic of a high $\mathrm{L}(\mathrm{L}>$.99).

We can also conclude that, following the guidelines of Exner, Kinder, and Curtis (1995), the possible examiner bias ( 1 examiner in the ANP, 2 in the DP and 3 in the NP groups), did not significantly alter the length of protocols obtained.

$D E P I \geq 6$. With regard to the presence of depression, we can schematically conclude that the Depression Index (DEPI) in Rorschach is not relevant in the ANP group; that is, that the D is not nuclear in the personality organization of these patients. The ANP group occupied an intermediate position between the DP group, where the presence of D is highly relevant, and the NP group, where the absence of D is equally relevant (Table 3 ).

Table 1

Percentage of Inter-scorer Reliability in Rorschach Test: Recommended and Obtained Agreement

\begin{tabular}{lccc}
\hline $\begin{array}{l}\text { Rorschach test } \\
\text { Segments }\end{array}$ & Exner \& Sendín, 1997 & Weiner, 1997 & $\begin{array}{c}\text { Obtained agreement } \\
\text { Actual research }\end{array}$ \\
\hline Location and developmental quality & Close to 100 & Higher than 90 & 93.5 \\
Determinants & Not lower than 80 & Around 80 & 85 \\
Form quality & 85 & Around 90 & 83.5 \\
Pair & Close to 100 & Higher than 90 & 98 \\
Contents & 85 & Around 90 & 92 \\
Popular responses & Close to 100 & Higher than 90 & 100 \\
Organizational-activity & Close to 100 & Higher than 90 & 96.5 \\
Special scores & Not lower than 80 & Around 80 & 82
\end{tabular}

Table 2

ANOVA for Rorschach Variables Related to Validity Criteria, Number of Responses, and Lambda

\begin{tabular}{lcccc}
\hline Variable & $F$ & Kruskal-Wallis & $h$ & Power \\
\hline Responses $^{a}$ & $2.62(p=.076)$ & $3.75(p=.154)$ & .20 & .60 \\
Lambda $^{b}$ & & $4.45(p=.108)$ & .14 & .25 \\
\hline
\end{tabular}

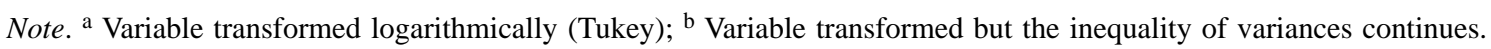

Table $2 \mathrm{~b}$

Means and Standard Deviations in Rorschach Validity Criteria, Number of Responses, and Lambda Variables

\begin{tabular}{lrrrrrr}
\hline \multirow{2}{*}{ Variable } & \multicolumn{2}{c}{ Non-patients } & \multicolumn{2}{c}{ Anorexic patients } & \multicolumn{2}{c}{ Depressed patients } \\
\cline { 2 - 6 } & $M$ & $S D$ & $M$ & $S D$ & \multicolumn{1}{c}{$M$} & $S D$ \\
\hline Responses & 24.98 & 9.01 & 22.44 & 5.91 & 21.56 & 6.11 \\
Lambda & 1.10 & 0.86 & 0.84 & 0.82 & 1.28 & 2.21 \\
\hline
\end{tabular}


Table 3

Chi-Square for Depression Index (DEPI), Coping Deficit Index (CDI), and Combinations of DEPI and CDI in the Rorschach Test

\begin{tabular}{lrcccccccc}
\hline \multirow{2}{*}{ Variable } & \multicolumn{3}{c}{ Statistics } & \multicolumn{2}{c}{ Non-patients } & \multicolumn{2}{c}{ Anorexic patients } & \multicolumn{2}{c}{ Depressed patients } \\
\cline { 2 - 9 } & $c^{2}$ & $C$ & $a$ & Present & Absent & Present & Absent & Present & Absent \\
\hline DEPI $\geq 5$ & 16.24 & .31 & $.000^{* * *}$ & 36 & 64 & 54 & 46 & 76 & 24 \\
DEPI $\geq 6$ & 9.86 & .25 & $.007^{* *}$ & 20 & 80 & 36 & 64 & 50 & 50 \\
CDI $\geq 4$ & 3.45 & .15 & .178 & 66 & 34 & 48 & 52 & 60 & 40 \\
DEPI $\geq 5+$ CDI $\geq 4$ & 10.10 & .25 & $.006^{* *}$ & 20 & 80 & 22 & 78 & 46 & 54 \\
DEPI $\geq 6+$ CDI $\geq 4$ & 7.23 & .21 & $.027^{*}$ & 16 & 84 & 14 & 86 & 34 & 66 \\
DEPI $\geq 5+$ CDI $<4$ & 3.95 & .16 & .139 & 16 & 84 & 32 & 68 & 30 & 70 \\
DEPI $\geq 6+$ CDI $<4$ a & 6.98 & .21 & $.031^{*}$ & 4 & 96 & 22 & 78 & 16 & 84 \\
DEPI $<5+$ CDI $\geq 4$ & 12.78 & .28 & $.002^{* *}$ & 46 & 54 & 26 & 74 & 14 & 86 \\
\hline
\end{tabular}

Note. ${ }^{\text {a }}$ The result is very doubtful due to the small number of subjects in one of the cells $(4 \%)$.

$* p<.05 . * * p<.01 . * * * p<.001$.

$C D I \geq 4$. This index did not help us to differentiate between the groups as it has quite a notable presence in the three groups. Many of the NP participants (66\%) often have difficulty coping effectively with the demands of their social environment and establishing adequate relational bonds. In contrast, the ANP group, although also typically ineffective when interacting with their environment, was less ineffective (48\%) than the other adolescents assessed.

DEPI and CDI. The simultaneous combination of the two indexes modified the previous results and indicates new and interesting differences between the adolescents studied. One characteristic of ANP is that, when D is present, it is not always related to problems regarding lack of social skills problems (Table 3, DEPI $\geq 6+\mathrm{CDI}<4$ ), whereas in DP the affective disorder of these patients is, on many occasions, linked to social difficulties (Table 3 , DEPI $\geq 6+\mathrm{CDI} \geq 4$ ).

It is important to note that, in NP adolescents, a more in-depth analysis of the DEPI and CDI indexes provides worrying results. In the cases where a severe affective disorder appears (DEPI $\geq 6=20 \%$ ), in a high percentage (16\%), depression seems to be related to coping deficit disorders (Table 3 , DEPI $\geq 6+\mathrm{CDI} \geq 4$ ). This data, together with the fact that, in general, this is a highly socially ineffective group (CDI $\geq 4=66 \%$ ), suggests the high probability for NP to develop some type of psychological disorder in the medium to long term. It seems appropriate to increase the NP group, in both number and representation. If a lack of resources for coping with a progressively complex world could be confirmed in larger groups, we would probably have to work on the prevention of pathology and maladjusted behaviors. If these findings could be generalized to a broader sector of the population, it would then be necessary to take preventive measures from other sectors, such as the educational sector, to provide our adolescents with better resources for facing the growing difficulties of their environment. Such action would consist of developing and fostering their social skills, assertive behavior, group activities and cooperation, problem-solving, decision-making, and so on; in other words, they should be provided with more psychological resources or be helped to use existing resources more effectively. This would promote a more satisfactory relationship with their environment, avoiding maladaptive behaviors (violence, drug abuse, etc.), as a means of evasion when faced with difficulties, and pathological behaviors, such as depression, suicide attempts, and so on.

When we analyzed the variables included in DEPI and CDI, we observed another peculiarity in the ANP group: the presence of a significant "Experience Actual", (EA $\geq 6$ $=62 \%, p<.05)$. EA is a derivation that relates to available resources. It is obtained by adding all Human Movement (M) and the weighted sum of the Chromatic Color responses (WSumC) together. In this case, it indicated that these anorexic adolescents showed good skills for deciding on their behaviors and carrying them out without losing control. However, when these skills come into contact with inadequate and even destructive behavior (not eating), such behavior is quite difficult to modify, and resistant to psychotherapeutic treatment.

C' > 2 and Sum SH. With regard to anxiety, Rorschach results indicated the absence of anxiety in the ANP group. There was no generalized anxiety, nor any notable emotional overload or marked internal suffering (C', $p<.05$; Sum SH, $p<.01)$. On the other hand, in the DP group, anxiety was present, which constitutes another difference between the two groups.

We can state at this point, then, that the differences between the ANP and DP groups on the Rorschach Test are quite obvious, and even more apparent if the less strict cutoff point of DEPI $\geq 5$ (Table 3) is used (Exner, 2001).

\section{MMPI}

Validity. The F-K > 11 index, indicating the simulation possibilities, had a very low presence in the ANP group (10\%) 
and in the DP group(12\%), and was totally absent in the NP group. This result indicates the low level of the $\mathrm{K}$ scale (Table $4 \mathrm{a}$ and $\mathrm{b}$ ) in the DP, as well as the scarce resources these adolescents have for coping with difficulties that arise.

Thus, we can observe that the ANP and the NP groups maintain similar adaptive and organizational levels (Table 4, F scale) and an appropriate balance between cooperation and caution before the examination process ( $\mathrm{K}$ scale , F-K $>11$ ), in contrast to the greater precariousness and disorganization of the DP group. That is, the ANP group is closer to normal functioning, while the DP group is closer to pathological functioning. Later, we see how this trend is repeated in the ANP group.

Scale 2. We can see (Table 4) that the presence of D in the ANP and DP groups is highly significant. When these adolescents described themselves, the depressive symptoms played an important role in their attributions. But a more detailed analysis of these data gives us additional information: The difference in percentages between the ANP and DP groups in this scale (18\%), subjected to the statistic PHI, reveals results close to statistical significance $(p=.05)$, indicating that, even if both groups describe themselves as having D symptoms, the DP group becomes considerably more depressed than the ANP group.

Scale 7. The DP group obtained statistically higher scores than the ANP and NP groups. This result confirmed the results obtained by the Rorschach Test, thus confirming the absence of anxiety in the ANP group.

Two-Point-Code Type. The 2-7/ 7-2 code type was not significantly present in any group $(\mathrm{DP}=14 \%$; $\mathrm{ANP}=4 \%$; $\mathrm{NP}=8 \%$ ). The most common code types were the following, although none of them were statistically significant:
DP: 2-1/ 1-2 (20\%) (1 = Hypochondria).

ANP: 2-3/ 3-2 (20\%) (3 = Hysteria); 2-1/ 1-2 (18\%).

NP: 5-9/ 9-5 (14\%) (5 = Masculinity-Femininity; $9=$ Hypomania). This code appeared to display substantially less psychopathology than other code types.

\section{$C B C L$}

Depressed (see Tables 5a and 5b). The parents of the ANP and DP groups gave higher scores in depressive symptoms to their daughters than the parents of the control group.

Anxious. While parents of the ANP group mentioned the presence of some anxiety in their daughters, the presence of anxiety was clearer in the DP group when the informing persons were the parents of these adolescents. Nevertheless, the obtained mean for the ANP group did not reach clinical significance.

By way of a brief summary, we can conclude the following:

The DP group: The agreement of the results is complete for the instruments used. These adolescents presented a globally depressive personality, as indicated by the Rorschach data. They described themselves as depressed on the MMPI, and they were perceived by their parents as showing depression symptoms in the CBCL. Anxiety was also present in all instruments.

The NP group: the results of the instruments used in the evaluation also match. The absence of depression and anxiety was statistically significant, as might be expected; these adolescents claimed not to be depressed or anxious, and their parents did not observe any symptoms of depression in them.

Table $4 \mathrm{a}$

ANOVA for Scale 2, Scale 7, Scale F, and Scale $K$ in MMPI

\begin{tabular}{lccccc}
\hline Variable & $F$ & Tukey & Kruskal-Wallis & $h$ & Power \\
\hline MMPI - b $^{\mathrm{b}}$ & & $47.58^{* * *}$ & .52 & 1.00 \\
MMPI $-7^{\mathrm{a}}$ & $9.97 * * *$ & DP > ANP and NP & $18.93^{* * *}$ & .36 & 0.99 \\
MMPI - F a & $7.25 * *$ & DP > ANP and NP & $13.35^{* *}$ & .32 & 0.90 \\
MMPI - K & $6.66 * *$ & ANP > DP & & .28 & 0.91 \\
\hline
\end{tabular}

Note. ${ }^{\mathrm{a}}$ Variables transformed logarithmically (Tukey). ${ }^{\mathrm{b}}$ Variables transformed but the inequality of variances continues.

$* * p<.01 . * * * p<.001$.

Table $4 \mathrm{~b}$

Means and Standard Deviations in MMPI Variables, Scale2, Scale7, Scale F, and Scale K

\begin{tabular}{lcccccc}
\hline \multirow{2}{*}{ Variable } & \multicolumn{2}{c}{ Non-patients } & \multicolumn{2}{c}{ Anorexic patients } & \multicolumn{2}{c}{ Depressed patients } \\
\cline { 2 - 6 } & $M$ & $S D$ & $M$ & $S D$ & $M$ & \multicolumn{1}{c}{ S } \\
\hline MMPI - 2 & 60.22 & 7.66 & 74.52 & 14.72 & 76.08 & 12.34 \\
MMPI - 7 & 53.56 & 11.12 & 56.12 & 15.90 & 66.00 & 14.02 \\
MMPI - F & 55.32 & 10.75 & 58.18 & 15.49 & 66.64 & 17.58 \\
MMPI - K & 47.38 & 11.75 & 51.28 & 9.76 & 43.88 & 8.68 \\
\hline
\end{tabular}


Table 5a

ANOVA for Depressed and Anxious Subscales in CBCL

\begin{tabular}{lccccc}
\hline Variable & $F$ & Tukey & Kruskal-Wallis & $h$ & Power \\
\hline $\begin{array}{l}\text { Depressed } \\
\text { Anxious }\end{array}$ & $7.21 * *$ & ANP and DP > NP & & .30 & .93 \\
\hline
\end{tabular}

Note. ${ }^{\mathrm{b}}$ Variable transformed but the inequality of variances continues.

$* * p<.01 . * * * p<.001$.

Table 5b

Means and Standard Deviations for Depressed and Anxious Subscales in CBCL

\begin{tabular}{lcccccc}
\hline \multirow{2}{*}{ Variable } & \multicolumn{2}{c}{ Non-patients } & \multicolumn{2}{c}{ Anorexic patients } & \multicolumn{2}{c}{ Depressed patients } \\
\cline { 2 - 7 } & $M$ & $S D$ & $M$ & $S D$ & $M$ & $S D$ \\
\hline Depressed & 65.68 & 7.76 & 71.02 & 6.61 & 70.58 & 8.87 \\
Anxious & 62.66 & 5.84 & 67.28 & 8.72 & 70.41 & 8.10 \\
\hline
\end{tabular}

The ANP group: there was an absence of anxiety, but different results in relation to the depression variable were obtained, depending on the tests used to evaluate it.

\section{Discussion}

The various results obtained with the ANP group in the depression variable (DEPI for the Rorschach Test and scale 2 for the MMPI) are based on valid and reliable psychometric measurements, with a high level of significance, good statistical power and medium effect sizes, which could hardly be rejected from a statistical point of view. It will therefore be necessary to look for a possible explanation for some of the apparently contradictory results mentioned above.

Some studies suggest that differences in the results are frequent when the Rorschach Test and the MMPI are used jointly (Weiner, 1993), because, even though they share psychometric properties, they are obtained through evaluations made from different approaches, and reveal different aspects of the evaluated personality (Meyer, 1997). The MMPI offers scores in 9 basic scales, which represent clinical aspects and allow for a global coded profile. The Rorschach Test provides information about habits, traits, styles, states, and other sets of variables for making an individualized description of a subject's personality. Thus, when the two tests are used in combination and their results do not coincide, the findings need to be integrated and explained (Weiner, 1993), the result being richer descriptions of the functioning of the personality of the evaluated subjects.

As stated at the beginning of this article, AN and D share a series of alterations in the biochemical mechanisms of neurotransmitters. These changes also appear in the presence of starvation and significant weight loss (Abou-Saleh,
Oleesky, Crisp, \& Lacey, 1986). In fact, in a third of the AN cases, the depressive symptoms disappear when the patient starts eating again (Morandé et al.,1995). According to these data, and knowing that scale 2 (MMPI) is highly saturated with items $(20 \%)$ mostly related to the physical aspects of depression (Levitt, 1989), an increase in scale 2 responses in the ANP group can be understood as this scales' greater sensitivity for detecting the psychological alterations produced by starvation. The Minnesota Group research carried out in the 1950s (Keys, Brozek, Henschel, Mickelsen, \& Taylor) supports this interpretation, as do more recent works mentioned by Toro (2001). These studies seem to suggest that in AN the therapeutic effectiveness of selective serotonin re-uptake inhibitors (SSRIs) is no greater than placebo. Nevertheless, SSRI administration after weight recovery significantly reduces relapse risk. This fact denotes the importance of starvation in symptomatology.

Obtained results also show the absence of a relevant number of subjects with DEPI $\geq 6$ in the ANP group, suggesting that there is no severe affective disorder affecting, either emotionally or cognitively, the psychological functioning of these adolescents. The validity of this index and the difficulty in its being altered deliberately, lend weight to this claim.

Considering all the information gathered in this study, we can thus conclude that, even though there are behaviors and depressive symptoms that may be reported by the ANP group (MMPI) and corroborated by their parents (CBCL), and which are probably related to starvation and weight loss, there is nonetheless, no basic severe affective problem (Rorschach Test) in the personality organization of these patients.

However, it is equally true that, although depression was not nuclear in the ANP group, it was more frequent in these participants than in the NP group (36\% versus $20 \%$, 
respectively, of DEPI $\geq 6$ on the Rorschach Test). Previous studies provide some explanatory hypotheses, which seem to be complementary rather than exclusive.

On the one hand, the previously mentioned effects of starvation and weight loss typical of an ANP, produce alterations in the biochemical mechanisms of the neurotransmitters (Abou-Saleh et al., 1986) which, at the same time, initiate depression, irritability, and so on (Fitcher, Pirke, \& Holsboer, 1986). According to Garfinkel and Garner (1982), the behaviors leading to a state of malnutrition in which the anorexic person finds herself (physiological aspect), constitute a determining factor in the psychological symptomatology.

There may also be an increase in the depressive pathology in the ANP due to hospitalization itself (Polaino \& Lizasoaín, 1990). This affective alteration is considered to be an adjustment process towards the disorders caused by hospitalization. It must be remembered that our ANP group was evaluated during the first days of their hospitalization, which, in most cases, occurred against the subjects' wishes, as they almost always consider such medical care unnecessary.

In the NP group, there were some depressed adolescents who had not generated any psychological help demand at all. We can assume a similar situation in the ANP group, that is, the presence of some depressed subjects who would have never asked for psychological help if an eating disorder (ED) had not also been present. In these cases, the D may precede the ED, and will probably act as a predisposing factor, favoring the development of anorexia (Katz, 1987).

Thus, within the anorexic pathology, it seems that two subgroups can be clearly differentiated: anorexia with D and anorexia without $\mathrm{D}$. This possibility is admitted and confirmed from various disciplines:

From biochemistry: Biederman et al., (1984) studied the platelet monoamine-oxidase activity (MAO) in a group of anorexic patients, finding significantly low MAO levels in the anorexic patients diagnosed with major depression, while non-depressed anorexic persons maintained MAO levels similar to those observed in the control group.

Clinical practice corroborates that, even though the treatment of an anorexic patient showing depressive symptomatology is initially easier due to suffering, which allows the patient to better accept the psychotherapeutic help provided, the presence or absence of D does not seem to improve the prognosis in the long term (North \& Gowers, 1999).

From the psychometric perspective: Biederman, Habelow, Rivinus, Harmatz, and Wise (1986) reviewed the MMPI results from a sample of anorexic patients, some of whom met the Research Diagnostic Criteria for depression (AN/RDC+) and some of whom did not (AN/RDC-), finding significant differences in the MMPI results of each group.

Our Rorschach results, obtained through the index analysis, can be interpreted in the same way, and lead us to confirm the existence of two clearly differentiated subgroups: the ANP who also presents depressive comorbidity (36\%) and the ANP without D (64\%). These results offer an empirical basis, from the perspective of the psychodiagnostic evaluation of the personality, for the difference between $\mathrm{AN}$ and D in regard to affective disorders. This statement runs counter to the opinion held by some authors (Gerner \& Gwirstman, 1981; Hudson, Pope, Jonas, \& Yurgelun-Tood, 1983), and matches that of other, more recent researchers, who admit these differences (López Gómez, 2001; Morandé et al., 1995; North \& Gowers, 1999; Toro, 2001; Turón, 1997).

The rates of depression in ANP appear to confirm our previous idea: Even if the same participants are studied, figures may differ depending on the measuring instrument (Rorschach, 36\%; MMPI, 56\%) or on the evaluation criteria (DEPI $\geq 6=36 \%$; DEPI $\geq 5=54 \%$ ). This is probably one of the main reasons why we find such varying percentages in the research on this topic.

Another noteworthy result is the absence of anxiety in the ANP group, revealed by the Rorschach Test and the MMPI results. The absence of anxiety and suffering in this group leads us to consider anorexic pathology as quite an egosyntonic disorder, and this is in accordance with what other authors report (Vallejo, 1997) about the characterpathology background of these patients, frequently observed in clinical practice, and which greatly obstructs the therapeutic approach and treatment. Other authors, however, (Lasa \& Canedo, 1997; Szmukler, Dare, \& Treasure, 1995; Turón, 1997; Yellowless, 1985) consider anxiety as a constant experience in ED. Parents of these patients refer to the presence of certain anxiety in their daughters (CBCL), but these observations probably allude to the tensions generated by family interaction, due to the conflict created between the anorexic person, who does not want to eat, and his/her family, who wants the child to eat at any price, despite the guidelines given by the professionals who treat them. They fall into a dynamic of persecution, control and suspicion, which greatly damages family life and creates extreme anxiety in the whole family, especially during meals and when talking about topics related to food and weight. The family is, in this way, contributing to the maintenance of the disorder.

The simultaneous combination of positive DEPI and CDI clusters has different implications in the three evaluated groups.

In the ANP group, the two indexes were not related. This finding is interesting, since many authors point to social inefficiency as a relevant aspect of AN (Bruch, 1962; Díaz \& Carrasco, 2001; Toro, 1995). However, in this research, even if these social deficits were confirmed in the ANP group, (CDI $\geq 4=48 \%$ ), figures were similar in the other groups, and only $14 \%$ of the ANP group with CDI $\geq 4$ also had a DPI $\geq 6$

In contrast, in the DP group, the two indexes were related, that is, in many cases, the affective disorder is linked to problems regarding lack of social skills. This finding has 
very important practical implications, since the ideal therapeutic intervention must focus on, in these cases, improving social skills rather than on the affective disorder, and no pharmacological treatment should be prescribed. Pharmacological treatment is useful in other types of depression, however, in these circumstances it is useless and probably harmful. Anti-depressant medication may lead to an improvement in the patient, not because of the administered drug itself, but because of the attention given when prescribing it and controlling it; the patient will, however, suffer a relapse when the treatment ends. It is always necessary to give precise and differentiated diagnoses in carrying out therapeutic actions, but this is of paramount importance when dealing with the youngest sectors of the population.

In spite of the potential difficulties involved, it would be very interesting to collect a sample of "successful" anorexic women (models, sportswomen, etc.), without a psychological/psychiatric history, in order to compare their results with those of anorexic patients. Could we hypothesize that the two groups would have similar depression rates?

Other research suggested by our data would involve confirming the existence of a Personality Disorder on the basis of AN. This would require a design with an older sample, since one cannot diagnose, correctly and definitively, a personality disorder in adolescents.

Finally, we should stress the importance of using a battery of tests when conducting research, rather than just a single test, no matter how valid it may be (Sendín, 2000). It is necessary to use complementary measures which, offering different behavior samples, reveal different aspects of the evaluated personality and make the issue under study more comprehensible. By using the Rorschach Test or MMPI exclusively, only a part of the problem would have been detected: the absence of $\mathrm{D}$, according to Rorschach, or the presence of D, according to the MMPI. Both of these findings reflect the truth, but neither, on its own, provides a full enough explanation of the complexity of eating disorders, so that the use of just one test would have given rise to partial, and therefore, simplistic or erroneous conclusions.

\section{References}

Abou-Saleh, M. T., Oleesky, D., Crisp, A. H., \& Lacey, J. H. (1986). Dexamethasone suppression and energy balance in eating disorders. Acta Psychiatrica Scandinavica, 73, 242-251.

Achenbach, T. M. (1979). The child behavior profile: An empirically based system for assessing children's behavioral problems and competencies. International Journal of Mental Health, 7, 2442.

Achenbach, T. M., \& Edelbrock, C. S. (1983). Manual for the child behavior checklist and revised child behavior profile. Burlington, VT: University of Vermont.
Altshuler, K. Z., \& Weiner, M. F. (1985). Anorexia nervosa and depression: A dissenting view. American Journal of Psychiatry, 142, 328-332.

American Psychiatric Association. (1987). Diagnostic and statistical manual of mental disorders ( $3^{\text {rd }}$ ed., Rev. ed.). Washington, DC: Author.

American Psychiatric Association. (1993). Practice guideline for eating disorders. American Journal of Psychiatry, 150, 212228.

American Psychiatric Association. (1994). Diagnostic and statistical manual of mental disorders (4th. ed.). Washington, DC: Author.

Archer, R. P. (1987). Using the MMPI with adolescents. Hillsdale, NJ: Erlbaum.

Archer, R. P. (1992). MMPI-A: Assessing adolescent psychopathology. Hillsdale, NJ: Erlbaum.

Berk, M., Kessa, K., Szabo, C. P., \& Butkow, N. (1997). The augmented platelet intracellular calcium response to serotonin in anorexia nervosa but not bulimia may be due to subsyndromal depression. International Journal of Eating Disorders, 22, 57-63.

Biederman, J., Habelow, W., Rivinus, T. Harmatz, J., \& Wise, J. (1986). MMPI profiles in anorexia nervosa patients with and without major depression. Psychiatry Research, 19, 147-154.

Biederman, J., Rivinus, T. M., Herzog, D. B., Ferber, R. A., Harper, G. P., \& Orsulak, P. J. (1984). Platelet MAO activity in anorexia nervosa patients with and without a major depressive disorder. American Journal of Psychiatry, 141, 1244-1247.

Bruch, H. (1962). Perceptual and conceptual disturbance in anorexia nervosa. Psychosomatic Medicine, 24, 187-195.

Cabetas, I. (1998). Anorexia nerviosa: la melancolía como sustrato psico-patológico de la enfermedad. Unpublished doctoral dissertation, University Complutense of Madrid, Spain.

Calderón, E. (2000). Trastornos de la personalidad en trastornos de la conducta alimentaría: anorexia nerviosa, bulimia nerviosa y trastorno de alimentación no especificado. Unpublished doctoral dissertation, University of Baleares Islands, Spain.

Cantwell, D. P., Sturzenberger, S., Burroughs, J., Salkin, B., \& Green, J. K. (1977). Anorexia nervosa: An affective disorder? Archives of General Psychiatry, 34, 1087-1093.

Cervera, S., \& Gual, P. (1998). Trastornos de la conducta alimentaría: anorexia nerviosa y bulimia nerviosa. In J. L. Vázquez-Barquero (Ed.), Psiquiatría en atención primaria (pp. 389-405). Madrid: Grupo Aula Médica.

Cervera, S., \& Quintanilla, M. (1995). Anorexia nerviosa: manifestaciones psicopatológicas fundamentales. Pamplona: Eunsa.

Chinchilla, A. (1995). Guía teórico-práctica de los trastornos de la conducta alimentaría: anorexia nerviosa y bulimia nerviosa. Barcelona: Masson.

Chinchilla, I. (1977). La anorexia nerviosa como equivalente depresivo. Unpublished doctoral dissertation, University of Salamanca, Spain.

Dana, R., \& Bolton, B. (1982). Interrelationships between Rorschach and MMPI scores for female college students. Psychological Bulletin, 51, 1281-1282. 
Dancyger, I. F., Sunday, S. R., \& Halmi, K. A. (1997). Depression modulates non eating disordered psychopathology in eating disordered patients. Eating Disorders: The Journal of Treatment and Prevention, 5, 59-68.

Díaz, M. (1999). Psicobiología de los trastornos de la conducta alimentaría. Aula Médica Psiquiatría, 3, 219-238.

Díaz, M., \& Carrasco, J. L. (2001). La personalidad y sus trastornos en la anorexia y en la bulimia nerviosa. In E. García-Camba (Ed.), Avances en trastornos de la conducta alimentaria. Anorexia nerviosa, bulimia nerviosa, obesidad (pp. 93-106). Barcelona: Masson.

Dies, R. R. (1995). Subject variables in Rorschach research. In J. E. Exner (Ed.), Issues and methods in Rorschach research (pp. 99-121). Mahwah, NJ: Erlbaum.

Exner, J. E. (1986). The Rorschach: A Comprehensive System. Basic foundations (Vol. 1, 2nd ed.). New York: Wiley.

Exner, J. E. (1991). The Rorschach: A Comprehensive System. Interpretation (Vol. 2, 2nd ed.). New York: Wiley.

Exner, J. E. (1993). The Rorschach: A Comprehensive System. Basic foundations (Vol. 1, 3rd ed.). New York: Wiley.

Exner, J. E. (1995). Introduction. In J. E. Exner (Ed.), Issues and methods in Rorschach research (pp. 1-24). Mahwah, NJ: Erlbaum.

Exner, J. E. (1997, July). Current research. Alumni Newsletter, 412.

Exner, J. E. (2001). A Rorschach workbook for the Comprehensive System (5th ed.). Asheville, NC: Rorschach Workshops.

Exner, J. E. (2003). The Rorschach. A Comprehensive System. Basic foundations and principles of interpretation (Vol. 1, 4th ed.). New York: Wiley.

Exner, J. E., Kinder, B. N., \& Curtis, G. (1995). Reviewing basic design features. In J. E. Exner (Ed.), Issues and methods in Rorschach research (pp. 145-158). Mahwah, NJ: Erlbaum.

Exner, J. E., \& Sendín, C. (1998). Manual de interpretación del Rorschach para el Sistema Comprehensivo (2 ${ }^{\mathrm{a}}$ ed.). Madrid: Psimática.

Exner, J. E., \& Sendín, C. (1997). Some issues in Rorschach research. European Journal of Psychological Assessment, 13, 155-163.

Exner, J. E., \& Weiner, I. B. (1995). The Rorschach: A Comprehensive System: Assessment of children and adolescents (Vol. 3, 2nd ed.). New York: Wiley.

Fitcher, M. M., Pirke, K. M., \& Holsboer, F. (1986). Weight loss causes neuroendocrine disturbances: Experimental study in healthy starving subjects. Psychiatry Research, 17, 61-72.

García Villamisar, D., \& Polaino, A. (1988). Una revisión del concepto de depresión infantil desde la perspectiva clínica. In A. Polaino (Ed.), Las depresiones infantiles (pp. 54-70). Madrid: Morata.

Garfinkel, P. E., \& Garner, D. M. (1982). Anorexia nervosa: A multidimensional perspective. New York: Brunner-Mazel.

Garner, D. M., \& Garfinkel, P. E. (1985). Handbook of psychotherapy of anorexia and bulimia. New York: Guilford Press.

Gerner, R. H., \& Gwirstman, H. E. (1981). Abnormalities of dexamethasone suppression test and urinary MHPG in anorexia nervosa. American Journal of Psychiatry, 138, 650.
Gershon, E. S., Schreiber, J. L., Guroff, J. J., Hamovit, J. R., Dibble, E. D., Kaye, W., Nurnberger, J. I., Andersen, A. E., \& Ebert, M. (1984). Clinical findings in patients with anorexia nervosa and affective illness in their relatives. American Journal of Psychiatry, 141, 1419-1422.

Gough, H. G. (1950). The F minus K dissimulation index for the MMPI. Journal of Consulting Psychology, 14, 408-413.

Greene, R. L. (1980). The MMPI: An interpretative manual. New York: Grune \& Stratton.

Halmi, K. A., Eckert, E., Marchi, P. A., Sampugnaro, V., Apple, R., \& Cohen, J. (1991). Comorbility of psychiatric diagnoses in anorexia nervosa. Archives of General Psychiatry, 48, 712718.

Hathaway, S. R, \& McKinley, J. C. (1942). A multiphasic personality schedule (Minnesota): III. The measurement of symptomatic depression. Journal of Psychology, 14, 73-84.

Hathaway, S. R., \& McKinley, J. C. (1951). Minnesota Multiphasic Personality Inventory manual (Rev. ed.). New York: The Psychological Corporation.

Hedges, L. V., \& Olkin, I. (1985). Statistical methods for metaanalysis. Orlando, FL: Academic.

Heebink, D. M., Sunday, S. R., \& Halmi, K. A. (1995). Anorexia nervosa and bulimia nervosa in adolescence: Effects of age and menstrual status on psychological variables. Journal of American Academy of Child and Adolescent Psychiatry, 34, 378-382.

Horiguchi, T., \& Sasaki, T. (1998). Rorschach study of borderline personality disorder: Construction of borderline personality index. Journal of Mental Health, 44, 69-74.

Hudson, J. I., Pope, H. G., Jonas, J. M., \& Yurgelun-Tood, D. (1983). Phenomenological relationship of eating disorders to major affective disorder. Psychiatry Research, 9, 345-354.

Katz, J. L. (1987). Eating disorders and affective disorder: Relatives or merely chance acquaintances? Comprehensive Psychiatry, 28, 220-228.

Keppel, G. (1991). Design and analysis: A researcher's handbook (2nd ed.). Englewood Cliffs, NJ: Prentice-Hall.

Keys, A., Brozek, J., Henschel, A., Mickelsen, O., \& Taylor, H. L. (1950). The biology of human starvation. Minneapolis, MN: University of Minnesota Press.

Klinefelter, D., Pancoast, D. L., Archer, R. P., \& Pruitt, D. L. (1990). Recent adolescent MMPI norms: T-scores elevation comparisons to Marks and Briggs. Journal of Personality Assessment, 54, 379-389.

Lasa, L., \& Canedo, C. (1997). Disfunciones fisiológicas relacionadas con factores mentales y del comportamiento: trastornos de la conducta alimentaria. In S. Cervera, V. Conde, A. Espino, J. Giner, C. Leal, \& F. Torres (Eds.), Manual del residente de psiquiatría (Vol.1, pp. 1121-1154). Madrid: Litofinter.

Lázaro, L., \& Toro, J. (1999). Aspectos epidemiológicos, sociales y culturales de los trastornos del comportamiento alimentario. Aula Médica Psiquiatría, 3, 205-218.

Levitt, E. E. (1989). The clinical application of MMPI special scales. Hillsdale, NJ: Lawrence Erlbaum Associates. 
López Gómez, I. (2001). Comorbilidad en los trastornos de la conducta alimentaria. In E. García-Camba (Ed.), Avances en trastornos de la conducta alimentaria. Anorexia nerviosa, bulimia nerviosa, obesidad (pp. 157-169). Barcelona: Masson.

Marks, P. A., \& Briggs, P. (1972). Adolescent norm tables for the MMPI. In W. G. Dahlstrom, G. S. Welsh, \& L. E. Dahlstrom (Eds.), An MMPI handbook: Clinical interpretation (Vol. 1, pp. 388-399). Minneapolis, MN: University of Minnesota Press.

Meyer, G. J. (1997). On the integration of personality assessment methods: The Rorschach and MMPI. Journal of Personality Assessment, 68, 297-330.

Morandé, G., Casas, J., Calvo, R., Marcos, A., Hidalgo I., Lareo, J. et al. (1995). Protocolo de trastornos del comportamiento alimentario. Madrid: Instituto Nacional de la Salud.

Mormont, Ch., Frankignoul, A., \& Michel, A. (2001). Le transsexualisme et l'anorexie mentale: Emprise et tyrannie de la subjectivite. Practiques Psychologiques, 3, 25-36.

Muttini, C. (2002). Bulimia e falso-se. Minerva Psichiatrica, 43, 1-10.

North, C., \& Gowers, S. (1999). Anorexia nervosa, psychopathology and outcome. International Journal Eating Disorders, 26, 386-389.

Parker, K. C., Hanson, R. K., \& Hunsley, J. (1988). MMPI, Rorschach, and WAIS: A meta-analytic comparison of reliability, stability, and validity. Psychological Bulletin, 103, 367-373.

Polaino, A., \& García Villamisar, D. A. (1988). Diagnóstico y evaluación de las depresiones infantiles. In A. Polaino-Lorente (Ed.), Las depresiones infantiles (pp. 71-96). Madrid: Morata.

Polaino Lorente, A., \& Lizasoaín, O. (1990). Programas para la preparación a la hospitalización infantile. In J. M. Buceta \& A. M. Bueno (Eds.), Modificación de conducta y salud (pp. 126-150). Madrid: Endema.

Pollice, Ch., Kaye, W. H., Greeno, C. G., \& Weltzin, T. E. (1997). Relationship of depression, anxiety, and obsession to state of illness in anorexia nervosa. International Journal of Eating Disorders, 21, 367-376.

Quay, H. C., \& Peterson, D. R. (1983). Interim manual for the Revised Behavior Problem Checklist. Coral Glabes, FL: Applied Social Sciences.

Roberts, N., Vargo, B., \& Ferguson, H. B. (1989). Measurement of anxiety and depression in children and adolescents. Psychiatric Clinics of North America, 12, 837-860.

Salorio, P., Ruiz, M. E., Martínez-Moya, R., Gómez, R., Velo, E., \& Oñate, A. (2003). Personalidad y trastornos alimentarios: un estudio mediante el test de Rorschach (Exner). Anales de Psiquiatría, 19, 1-4.
Sánchez Carrión, J. J. (1992). Análisis de tablas de contingencia (2nd ed.). Madrid: Centro de Investigaciones Sociológicas.

Sánchez Carrión, J. J. (1995). Manual de análisis de datos. Madrid: Alianza Editorial.

Sendín, C. (2000). Diagnóstico psicológico. Bases conceptuales y guía práctica en los contextos clínico y educativo. Madrid: Psimática.

Sendín, C., \& García-Alba, C. (1995, November). Diagnóstico escolar: integración de Rorschach y Escala de Inteligencia de Wechsler para Niños (WISC) para la medida del desarrollo cognitivo. Paper presented at the 2nd International Congress on Psychology and Education, Madrid, Spain.

Szmukler, C., Dare, C., \& Treasure, J. (1995). Handbook of eating disorders. Theory, treatment and research. New York: Wiley.

Toro, J. (1995). Los trastornos oroalimentarios. In J. Rodríguez Sacristán (Ed.), Psicopatología del niño y del adolescente (Vol. 1, pp. 429-454). Sevilla: Publicaciones de la Universidad de Manuales Universitarios.

Toro, J. (2001). Anorexia nerviosa. Medicina Clínica, 117, 334335.

Turón, V. (1997). Trastornos de la alimentación: Anorexia nerviosa, bulimia y obesidad. Barcelona: Masson.

Vallejo, J. (1997). Prólogo. In V. Turón (Ed.), Trastornos de la alimentación (p. IX). Barcelona: Masson.

Varela, M., Martíni, A. M., Ponce, M., \& Rubio, X. (1994). Anorexia nerviosa: estudio clínico-fenomenológico de siete casos. Revista de Psiquiatría Clínica, 31, 25-34.

Viglione, D. J. (1997). Problems in Rorschach research and what to do about them. Journal of Personality Assessment, 68, 590599.

Weiner, I. B. (1993). Clinical considerations in the conjoint use of the Rorschach and the MMPI. Journal of Personality Assessment, 60, 148-152.

Weiner, I. B. (1997). Current status of the Rorschach inkblot method. Journal of Personality Assessment, 68, 5-19.

Winokur, A., March, V., \& Mendels, J. (1980). Primary affective disorder in relatives of patients with anorexia nervosa. American Journal of Psychiatry, 137, 695-698.

Yellowless, A. J. (1985). Anorexia and bulimia in anorexia nervosa: A study of psychosocial functioning and associated psychiatric symptomatology. British Journal of Psychiatry, 146, 648-652.

Received February 4, 2003

Revision received November 14, 2003

Accepted December 15, 2004 
